\title{
Depressed Skull Fractures Overlying Dural Venous Sinuses: Management Modalities and Review of Literature
}

\author{
Mohamed Mostafa AZIZ, Shafik Tahseen EL MOLLA, Hisham Anwer ABDELRAHIEM, \\ Osama Mohammed DAWOOD
}

Ain Shams University, Department of Neurosurgery, Cairo, Egypt

Corresponding author: Mohamed Mostafa AZIZ mohamed.kotb@med.asu.edu.eg

\section{ABSTRACT}

AIM: To characterize the sociodemographic, clinical and radiological findings of patients with depressed skull fractures overlying cranial dural sinuses that we have faced in our institute. In addition, to explore the indications and choices for the surgical and nonsurgical management of such cases, and assess outcomes in these two treatment groups.

MATERIAL and METHODS: We prospectively followed up a cohort of 34 patients with fractures over dural venous sinuses from January 2013 to December 2017. Twelve (35.1\%) were simple depressed fractures (SDFs) and 22 (64.7\%) were compound depressed fractures (CDFs). Eighteen patients (52.9\%) were treated surgically, and $16(47.1 \%)$ were treated conservatively.

RESULTS: The mean age was 20.8 years. Thirty-two of the patients were males (94.12\%). The mean time from trauma until hospital arrival was 3.8 hours, and the mean admission Glasgow Coma Score (GCS) was 13.7. Direct trauma was the most common mode of injury. Funduscopy was performed in 16 patients (47.1\%), and magnetic resonance venography (MRV) in four patients (11.8\%). Twenty-four patients $(70.59 \%)$ had the fracture overlying the superior sagittal sinus (SSS). The mean length of hospital stay was five days, and the mean follow-up duration was 6.8 months. Twenty-eight patients $(82.35 \%)$ had a good recovery.

CONCLUSION: The majority of SDFs and some CDFs overlying dural sinuses can be managed safely without major surgical intervention. Conservation should be favored when the sinus is patent, dura intact, and bone displacement is insignificant in neurologically intact patients with an apparently clean wound. Otherwise, surgery should be considered. We also propose including a funduscopic examination and venogram as parts of the initial trauma work-up for these patients.

KEYWORDS: Craniocerebral trauma, Compound depressed skull fracture, Dural sinuses injury, Simple depressed skull fracture

\section{INTRODUCTION}

$\mathrm{T}$ The management of fractures overlying cranial venous sinuses remains a major challenge to neurosurgeons. The difficulty posed by these fractures relates to the potential morbidity associated with conservative treatment, and the risk associated with surgery. An estimated $10 \%$ of skull fractures involve cerebral venous sinuses (15), with $15 \%$ being compound depressed (16). The management of these fractures requires both good judgment and experience because controversy exists regarding indications, and there are no definite rules that apply due to the diversity in presentations (8).
There are two popular strategies for management: surgical treatment (10), where the fracture can be carefully elevated, trying to gain control of the venous sinus as soon as possible, preparing for significant transfusion requirements if needed, or, alternatively, conservative treatment if the fracture site is not contaminated grossly with foreign materials, or will not lead to a major cosmetic or functional deformity, or not causing intracranial hypertension secondary to sinus occlusion (17). Conservative management includes scalp debridement alone with irrigation, followed by serial follow-up CT scans for any signs of brain abscess (8). However, a wide range of complications have been reported with conservative
Mohamed Mostafa AZIZ CD : 0000-0003-4898-7396 Shafik Tahseen EL MOLLA (D) : 0000-0002-8962-6346
Hisham Anwer ABDELRAHIEM (10 : 0000-0001-6700-4442

Osama Mohammed DAWOOD (1D): 0000-0002-8530-7145 
management, for example: venous sinus stenosis leading to venous hypertension and increased intracranial pressure $(3,4,6,7,18-20)$, sinus thrombosis leading to late deterioration (11), benign intracranial hypertension $(3,6,7,20)$, and even hemorrhagic infarction (13).

Faced with this therapeutic dilemma of conservation versus surgery for fractures overlying dural venous sinuses, and the lack of sufficient data in the literature regarding this neurosurgical problem, we present a meticulously followed-up cohort in the hope that we may draw some conclusions that throw more light on their indications and outcomes.

The aim of this study was to characterize the sociodemographic, clinical and radiological findings of patients with depressed fractures overlying cranial dural sinuses that we have faced in our institute, which is a major trauma referral center. Also, we would like to explore the indications and choices for the surgical and non-surgical (conservative) treatment for depressed fractures overlying calvarial dural venous sinuses, and assess outcome in the two treatment groups.

\section{MATERIAL and METHODS}

\section{Study Design}

A prospective cohort study (5) was conducted in our department of neurosurgery from January 2013 to December 2017. During that four-year period, 34 patients with depressed skull fractures over different calvarial dural venous sinuses were managed in our department; 12 (35.3\%) were simple and $22(64.7 \%)$ were compound fractures. Eighteen patients $(52.9 \%)$ were surgically treated, while $16(47.1 \%)$ had the chance to be treated conservatively. However, our primary aim was not to compare both treatment options since their indications are different, but to further explore the indications and assess outcomes in both management groups.

\section{Treatment Options}

\section{Conservative treatment}

This group consisted of local scalp wound debridement, irrigation and primary closure, followed by antibiotic administration for an appropriate period. Serial CT scans were carried out over the next two to three months to check for any signs of delayed abscess formation (1). Nonsurgical treatment was chosen when there were no clinical or radiological signs of violation of the dura mater, or sizable intracranial hematoma, nor evidence of exposed brain or cerebrospinal fluid leakage, pneumocephalus related to the fracture, depressed bone fragments over $1 \mathrm{~cm}$ below the inner table of the skull, no evidence of wound infection, no gross wound contamination or cosmetic deformity (21).

\section{Surgical treatment}

Standard surgical techniques for management of fractures over dural venous sinuses as described by Geisler and Manson (8), and Zacko et al. (21) were used, however with some modifications according to each case.
All surgery was performed in the emergency operating room prepared with an operating table with an easily maneuverable head. In this way, venous pressure could be easily lowered to decrease bleeding, and raised to prevent air embolism. Personnel and materials were put in place to deal with potentially major hemorrhagic events just as in any operative procedure involving the sinuses. All precautions were taken to prevent venous obstruction in the neck by avoiding extremes of flexion and rotation of the head on the shoulders. At least two to four units of packed red blood cells (RBCs) were made available in the operating room should the need for transfusion arise.

To decompress the venous sinus from any depressed bone fragments, sufficient bone was removed around the margins of the sinus with rongeurs. This allowed proximal and distal control of the sinus. Dural repair was required only in two cases. Continuous copious irrigation of saline was used to prevent air embolism, and patient pressure tamponade with Surgicel and Gelfoam was used to achieve hemostasis, after which the depressed bone fragments were replaced with a miniplate system, or fixed by sutures. A triple antibiotics regimen consisting of parenteral: penicillin + second generation cephalosporins + metronidazole was administered over five to seven days, or the period of hospitalization, for cases with penetrating injuries. Oral antibiotics were continued for a further week at home.

\section{Clinical and Imaging Assessment}

During hospital stays all nonsurgical cases were placed under close observation for any deterioration resulting from sinus obstruction or thrombosis. After discharge, follow-up visits were scheduled at one week, and one, two to three, six and twelve months, according to our departmental protocol for both groups. All patients were subjected to thorough neurological examination and follow-up CT brain scans. Any new neurological or radiological signs in either treatment groups were reported and managed accordingly.

\section{Statistical Analysis}

STATA version 10.1 was used for statistical analysis.

\section{RESULTS}

\section{Patients' Demographics}

A total of 34 patients were included in our study; 32 males $(94.12 \%)$ and 2 females (5.9\%). The mean age was $20.8 \pm 11.5$ years, and there wasn't any statistically significant difference between patients in the surgical and non-surgical treatment groups. Eighteen patients $(52.9 \%)$ were of the pediatric age group (age $\leq 18$ years) (Table l).

\section{Trauma and Clinical Presentation}

Direct trauma (direct hit or object falling on head) $(n=20$, $58.8 \%$ ) was the most common mode of injury, followed by road traffic accidents $(n=8,23.5 \%)$. Falling from a height came last in frequency $(n=6,17.65 \%)$. The mean time \pm SD from trauma until arrival to the hospital was $3.8 \pm 1.5$ hours and the mean $( \pm S D)$ admission Glasgow Coma Score was $13.7 \pm 1.96$, 
with a range between 10 and 15. Twenty-eight patients were neurologically intact on admission and six had motor deficits (Table I).

\section{Fracture:}

Twelve (35.3\%) patients had simple depressed fractures, whereas twenty-two (64.7\%) had compound depressed

Table I: Patients Characteristics

\begin{tabular}{|c|c|c|}
\hline Variable & Frequency (n) & $\%$ \\
\hline \multicolumn{3}{|l|}{ Sex } \\
\hline Males & 32 & 94.12 \\
\hline Females & 2 & 5.88 \\
\hline \multicolumn{3}{|l|}{ Mode of Trauma } \\
\hline Direct Trauma & 20 & 58.82 \\
\hline Road Traffic Accident & 8 & 23.53 \\
\hline Fall from Height & 6 & 17.65 \\
\hline \multicolumn{3}{|c|}{ Pre-treatment Neurological status } \\
\hline Intact motor power & 28 & 82.5 \\
\hline Paresis & 6 & 17.5 \\
\hline
\end{tabular}

Table II: Fracture Type and Location

\begin{tabular}{lcc}
\hline Variable & Frequency (n) & $\%$ \\
\hline Fracture Type & & \\
\hline Simple Depressed & 12 & 35.29 \\
\hline Compound Depressed & 22 & 64.71 \\
\hline Fracture Site & & \\
\hline Superior Sagittal Sinus (SSS) & 24 & 70.59 \\
\hline SSS-Anterior & 12 & 35.29 \\
\hline SSS-Middle & 8 & 23.53 \\
\hline SSS-Posterior & 4 & 11.76 \\
\hline Confluence of Sinuses & 8 & 23.53 \\
\hline Transverse Sinus & 2 & 5.88 \\
\hline
\end{tabular}

Table III: Distribution of Fracture Type by Site of Sinus Involvement

\begin{tabular}{cccc}
\hline Site & $\begin{array}{c}\text { Confluence } \\
\text { of sinuses }\end{array}$ & $\begin{array}{c}\text { Superior } \\
\text { Sagittal }\end{array}$ & $\begin{array}{c}\text { Transverse } \\
\text { Sinus }\end{array}$ \\
& $\mathbf{n}(\%)$ & Sinus $\mathbf{n}(\%)$ & $\mathbf{n}(\%)$ \\
\hline
\end{tabular}

\section{Fracture Type}

\begin{tabular}{lrrl}
\hline Simple & $4(50)$ & $8(33.33)$ & 0 \\
\hline Compound & $4(50)$ & $16(66.67)$ & $2(100)$ \\
\hline
\end{tabular}

fractures (Table II). Twenty-four patients (70.59\%) had the fracture overlying the superior sagittal sinus (SSS), of which twelve (35.29\%) were anterior. In eight patients $(23.53 \%)$ the fracture overlaid the torcular herophili and two patients had fractures on the transverse sinus. The distribution of fracture type by site involvement is shown in Table III.

\section{Work up:}

All patients had a CT scan on admission. Fundus was examined in 16 patients (47.1\%); those who were managed conservatively, and magnetic resonance venography (MRV) was performed in 4 patients (11.8\%) (Table IV).

\section{Treatment and outcome:}

Of the 18 patients treated surgically, 14 had compound depressed fractures (CDF); of the 16 patients who received non-surgical therapy, 8 had simple depressed fractures (SDF) (Table V).

Surgery was favored when the fracture was anterior (Table $\mathrm{VI})$. The most common indications for surgery were displaced bone fragments with a breach in the dura (Table VII).

The mean length of hospital stay was $5.06 \pm 2.22$ days (minimum 3, maximum 10 days) and the follow-up duration

Table IV: Paraclinical Investigations: MRV, Fundus and CT Scan of Brain

\begin{tabular}{lcc}
\hline Variable & Frequency (n) & $\%$ \\
\hline \multicolumn{1}{l}{ MRV } & & \\
\hline Yes & 4 & 11.76 \\
\hline No & 30 & 88.24 \\
\hline Fundus Examination & & \\
\hline Yes & 16 & 47.1 \\
\hline No & 18 & 52.9 \\
\hline CT Scan Brain & 34 & 100 \\
\hline Associated cranio-cerebral Lesions & & \\
\hline Contusion & 6 & 17.6 \\
\hline Orbital Fracture & 2 & 5.9 \\
\hline None & 26 & 76.5 \\
\hline
\end{tabular}

MRV: Magnetic resonance venography, CT: Computed tomography.

Table V: Treatment Option for the Fracture Type

\begin{tabular}{cccc}
\hline & Conservation & Surgery & \\
\hline Fracture Type & & & \\
\cline { 1 - 3 } Simple & $8(66.7)$ & $4(33.3)$ & $0.335^{\star}$ \\
\cline { 1 - 3 } Compound & $8(36.4)$ & $14(64.6)$ & \\
\hline
\end{tabular}

${ }^{*}$ Fisher's exact. 
Table VI: Therapeutic Option by Fracture Location

\begin{tabular}{lcccccc}
\hline $\begin{array}{l}\text { Fracture location } \\
\text { Treatment option (n) }\end{array}$ & Anterior SSS & Middle SSS & Posterior Ss & $\begin{array}{c}\text { Confluence of } \\
\text { Sinuses }\end{array}$ & $\begin{array}{c}\text { Transverse } \\
\text { sinus }\end{array}$ & $\begin{array}{c}\text { Total } \\
\text { Surgery }\end{array}$ \\
\hline Conservative & 10 & 2 & 2 & $2^{*}$ & 2 & 18 \\
\hline Total & 2 & 6 & 2 & 6 & 0 & 16 \\
\hline
\end{tabular}

${ }^{*}$ Fractures were compound depressed with bone fragments just touching the intact confluence.

Table VII: Indications for Surgery and Conservative Treatment Per Type of Depressed Fracture

\begin{tabular}{|c|c|c|}
\hline & $\begin{array}{c}\text { Conservation } \\
(n=16)\end{array}$ & $\begin{array}{l}\text { Surgery } \\
(n=18)\end{array}$ \\
\hline Simple Depressed Fracture (SDFs) & $\begin{array}{l}\text { Mild bone displacement }+ \text { patent sinus } \\
\qquad(\mathrm{n}=8)\end{array}$ & $\begin{array}{c}\text { Bone Displaced }(n=2) \\
\text { Bone Displaced + Breached Dura }(n=2)\end{array}$ \\
\hline $\begin{array}{l}\text { Compound Depressed Fracture } \\
\text { (CDFs) }\end{array}$ & $\begin{array}{l}\text { Clean Wound + Mild bone displacement } \\
\text { and intact dura }(n=8)\end{array}$ & $\begin{array}{c}\text { Displaced Bone + Breached Dura }(n=8) \\
\text { Displaced Bone + Breached Dura + } \\
\text { Neurologic Deficit }(n=4) \\
\text { Displaced Bone + Neurologic Deficit }(n=2)\end{array}$ \\
\hline
\end{tabular}

Table VIII: Length of Hospital Stay and Follow-Up Duration

\begin{tabular}{|c|c|c|c|c|c|}
\hline Group & $\mathbf{n}$ & Mean \pm Std. Dev. & \multicolumn{2}{|c|}{ [95\% Conf. Interval] } & $\mathbf{p}$ \\
\hline All patients & 34 & $5.06 \pm 2.22$ & 3.91 & 6.2 & \\
\hline Conservation & 16 & $4.3 \pm 1.4$ & 3.1 & 5.4 & \multirow{2}{*}{$0.16^{\star}$} \\
\hline Surgery & 18 & $5.8 \pm 2.6$ & 3.8 & 7.8 & \\
\hline \multicolumn{6}{|l|}{ Follow-up/months } \\
\hline All patients & 34 & $6.8 \pm 2.7$ & 4.3 & 8.9 & \\
\hline Conservation & 12 & $6.6 \pm 2.7$ & 4.3 & 8.9 & \multirow{2}{*}{$0.79^{*}$} \\
\hline Surgery & 22 & $6.9 \pm 1.2$ & 5.99 & 7.8 & \\
\hline
\end{tabular}

*Two-sample $t$ test with equal variances.

Table IX: Outcome on Discharge (Glasgow Outcome Score) (9)

\begin{tabular}{lccc}
\hline Outcome & GOS & Frequency & $\begin{array}{c}\text { Percentage } \\
\text { (\%) }\end{array}$ \\
\hline Good recovery & 5 & 28 & 82.35 \\
\hline Mild disability & 4 & 4 & 11.76 \\
\hline Moderate disability & 3 & 2 & 5.88 \\
\hline Severe disability & 2 & 0 & 0 \\
\hline Dead & 1 & 0 & 0 \\
\hline
\end{tabular}

was $6.8 \pm 2.7$ months (minimum 3 , maximum 11 months) (Table VIII). There was no statistically significant difference in both treatment groups ( $p>0.05$ ).

Twenty-eight patients (82.35\%) had a good recovery (Table IX). Of the six patients with pre-treatment weakness (two grade 4, and four grade 3), the four with grade 3 weaknesses improved to grade 4 . No mortality was registered in our cohorts.

The illustrated cases are shown in Figures 1 and 2.

\section{DISCUSSION}

Depressed fractures overlying dural venous sinuses are common in routine neurosurgical practice, representing $10 \%$ of skull fractures (15). Previous reports from our setting indicated a $15.6 \%$ incidence for compound depressed fractures (30/192 over two years) (16). Other series have reported an $11.5 \%$ and $18 \%$ incidence of CDFs $(10,12)$.

The mean age of our cohort was 20.8 years, with 18 patients $(52.9 \%)$ in the pediatric age group ( $\leq 18$ years). Our results are similar to those of the study by Taghyan et al. that was conducted in a different region (rural) from our setting; they explained this demographic profile to be related to falls and 


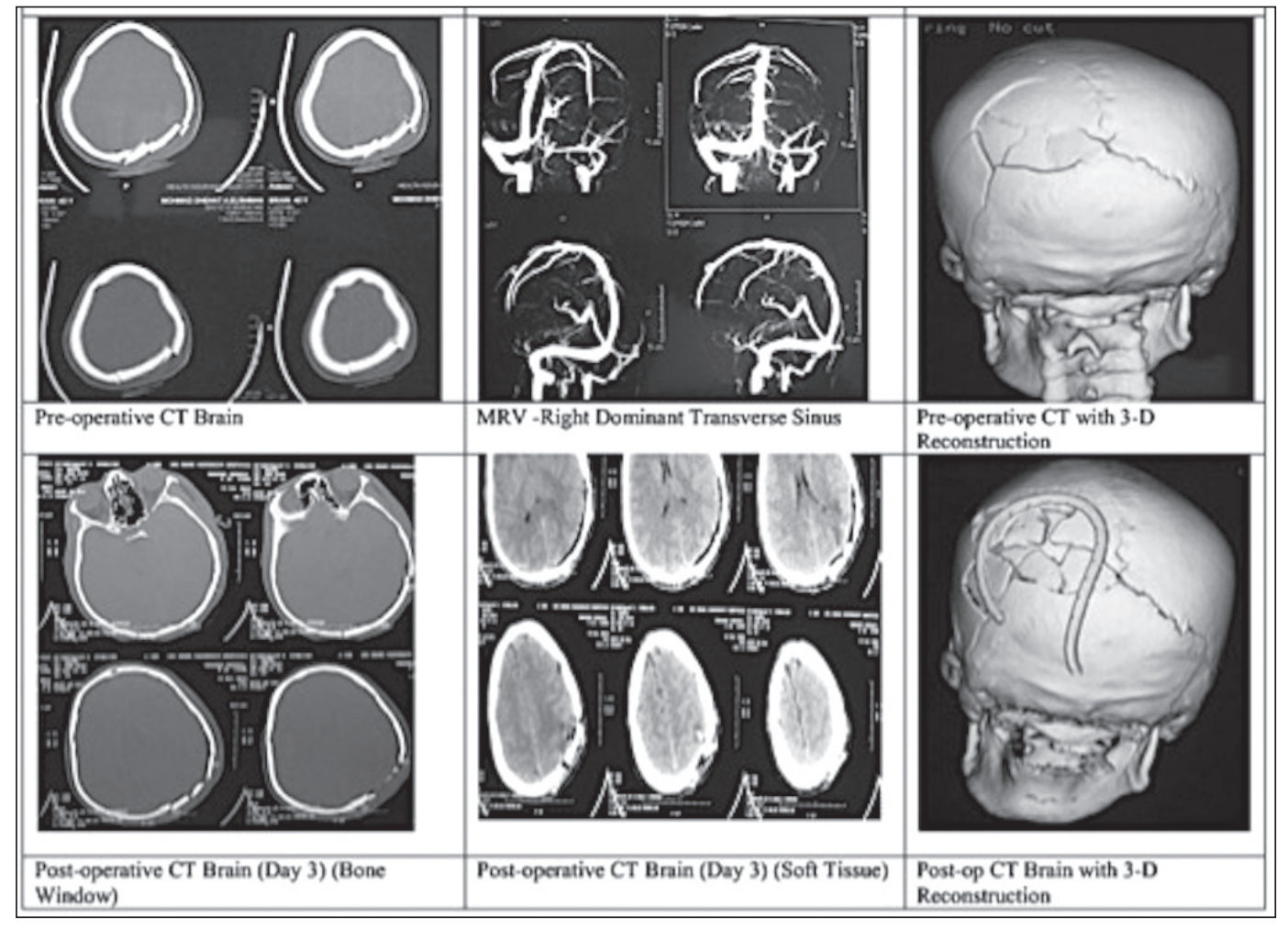

Figure 1: Surgically managed compound depressed fracture.
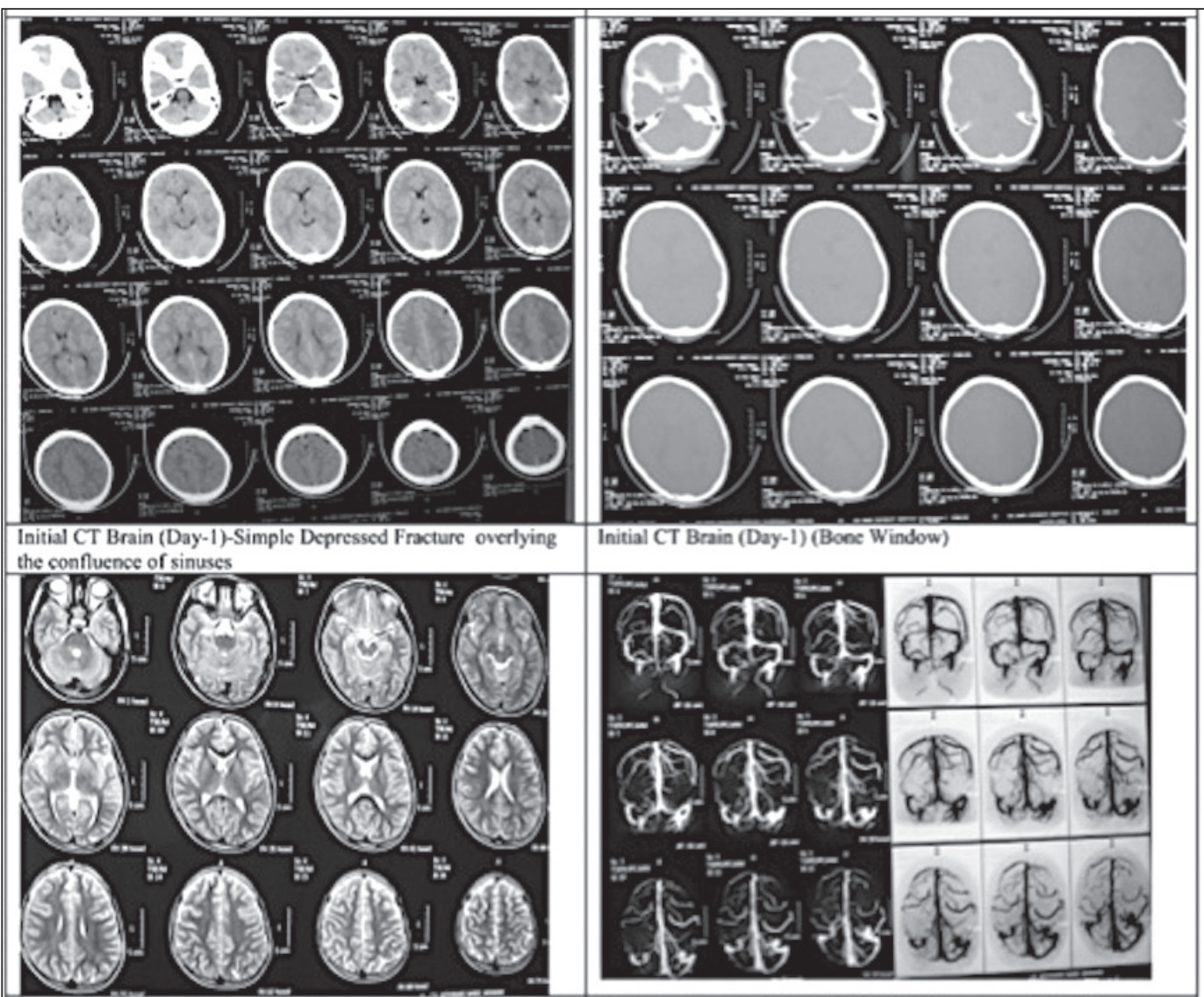

Initial CT Brain (Day-1) (Bone Window)

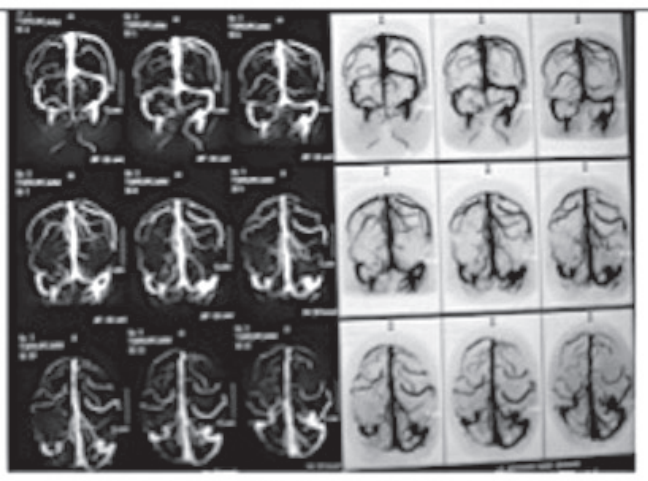

MRV Brain (Day-14 Post Trama)-Patent Confluence and left transverse sinus. Probuble hypoplastic right transverse sinus with well developed collaterals.

Figure 2: Conservatively managed simple depressed fracture overlying torcular herophili. 
assaults (16). We couldn't give any plausible explanation for our cohort, since our hospital receives a mixture of patients from all walks of life.

Thirty-two (94.12\%) of our patients were male, and there were only two females $(5.9 \%)$, a finding that has been corroborated in previous studies within $(16)$, and without $(2,10,14)$ our setting, and probably related to environmental, occupational and cultural factors.

Twelve patients $(35.29 \%)$ had simple depressed fractures. Direct trauma (direct hit or object falling on head) [ $\mathrm{n}=20(58.8 \%)]$ was by far the most common mode of injury, explained by the fact that assailants often face each other, and falls consisted mostly of either a brick or metal object striking the head from a height.

The mean time from trauma until arrival to hospital was 3.8 hours (minimum 2, maximum 7 hours), and there was no statistically significant difference between patients managed surgically and conservatively. The mean $( \pm S D)$ admission GCS was $13.7 \pm 1.96$, findings similar to previously published series (16). Cases with low GCS were compound depressed fractures with underlying brain injury.

Twenty-eight patients (82.5\%) had no neurologic deficit on initial clinical examination. The six cases with deficits (two with grade 4 and four with grade 3 weaknesses) were cases of CDFs involving the anterior, posterior SSS and transverse sinus.

Depressed cranial fractures can be classified into two major types: simple depressed fractures, which have no galeal injury, and compound depressed fractures, which have galeal injury and an overlying scalp laceration in connection with the fracture site (1).

Depressed skull fracture may cause dural venous sinus occlusion either by penetration or compression against the outer wall. The clinical picture of early venous sinus occlusion is nonspecific, may occur late, and may not be not associated with the parenchymal abnormalities related to venous insufficiency on either CT and/or MRI. However, brain MRV can provide good anatomic detail of the deep and superficial intracranial venous system, and can be used to demonstrate filling defects. However, common variants of the venous sinuses system should not be mistaken for sinus thrombosis. Fundus examination was routinely performed in cases managed conservatively to detect signs of intracranial hypertension.

Venous hypertension and increased intracranial pressure $(3,4,6,7,18-20)$ from venous sinus narrowing or sinus thrombosis (11), is a late complication associated with depressed fractures overlying venous sinus.

In 22 patients (64.7\%) the fracture was compound and in 12 $(35.3 \%)$ it was closed. The SSS was the most involved dural sinus $(n=24,70.59 \%)$, most of which were anterior $(n=12$, $35.29 \%$ ), while the rest were in the middle and posterior SSS. Two cases involved the transverse sinus. In the series by Ozer et al. the majority of cases of depressed fracture were localized over the SSS, and half were over the middle one-third sinus (14), results that are similar to those of other reported series (16). This could be explained by the previously explained mechanism of injury in the majority of our patients a direct hit or a falling object striking the head.

CT brain with bone window and plain x-ray of cervical spine were conducted in all patients immediately on arrival. Associated cranio-cerebral lesions were found in eight patients (two with orbital fractures with CDF over anterior SSS and six others with underlying brain contusions). MRV was performed in four patients $(11.76 \%)$ to assess the patency of the SSS. Fundus examination (FE) was carried out in the $16(47.1 \%)$ patients who were managed conservatively to exclude intracranial hypertension. Serial FE was also carried out in these patients to help detect late onset of intracranial hypertension as described in many series $(3,4,6,7,20)$.

With regard to treatment, 14 of the 22 patients with CDFs were managed surgically, while 8 of the 12 patients with SDFs were managed conservatively. The indications for the different treatment modalities are shown in Table VII.

In our cohort, for SDFs, conservative treatment was the option of choice in patients for whom CT brain scans showed little or mild displacement of the outer skull table and a patent sinus. Surgery was commonly indicated when the outer table was displaced beyond the inner table and/or breaching of dura.

For CDFs, conservation was often the preferred option when the wound was considered clean, with little or mild bone displacement and intact dura. Surgery was considered in cases with displaced bone and/or breached dura and/or neurologic deficit, and when the fracture was anteriorly located.

The management of these fractures requires both experience and good judgment as no definite rules apply to the variation of presentations (8). It has been a common neurosurgical wisdom that depressed skull fractures over the SSS should not be elevated because it carries the risk of fatal venous hemorrhage (19).

Depressed calvarial fractures overlying the major venous sinus with the absence of a CSF fistula or an associated intracranial hematoma are often managed conservatively because of the associated high risks of major sinus bleeding, especially if a depressed bone fragment has been closing a sinus tear or sinus occlusion and venous infarction $(1,11)$. Elevating depressed skull fractures overlying a cranial venous sinus is hazardous (18). Local wound debridement and closure are almost sufficient in these cases (1).

However, not all cases can be treated conservatively as some cases may involve foreign bodies (11). The surgical management of depressed fractures is indicated when a venous sinus has been occluded by the depressed bone resulting in increased intracranial pressure (19), and might also be needed in rare circumstances of delayed intracranial hypertension $(3,7)$. The fracture should be carefully elevated, attempting to gain best control of the venous sinus as soon as possible, preparing for the possibility of significant transfusion requirements (8). All cases with surgical fractures were treated 
by elevation and debridement. Ten of the surgically treated patients received blood transfusion per-operatively with eight received up to two units of packed RBCs. Sinus bleeding is a known common complication rendering this operation difficult (12), a hazard that might even lead to aborting the operation (17). Primary bone fragment replacement of large bony fragments was performed in all cases, as none of our cases had an apparent wound infection at the time of surgery. Several studies have recorded that the rate of postoperative infection is not increased by primary bone fragment replacement (2).

All of our patients received their surgery or local debridement within 12 hours of arrival to the hospital. There was no recorded difference in the rate of postoperative infection between patients with skull fractures undergoing surgical repair within eight hours and those treated after that time (1).

Anticonvulsant drugs were administered prophylactically to patients with a breached dura during the early post-operative period or cerebral lesion.

A few additional points merit mention; the sagittal sinus can be safely transected in its anterior third, should this become necessary. This was carried out in two of our patients with orbital and anterior skull base fracture. The sagittal sinus can be repaired in its middle and posterior third.

Sometimes, depressed fractures overlying major venous sinuses are associated with intracranial hematomas. Posterior fossa extradural hematomas, which usually extend above and below the tentorium, account for approximately 5\% to $10 \%$ of these lesions. Our two patients with fractures involving the transverse sinus had no associated hematoma.

All management protocols for compound depressed fractures should include antibiotics $(1,17)$. All our patients with CDFs started parenteral triple antibiotics: a penicillin + second generation cephalosporins + metronidazole during the first week. In addition, parenteral paracetamol as analgesic, anticonvulsant (if breaching of dura or underlying brain lesion) and ranitidine was started. Mannitol and Furosemide were given if features of raised intracranial pressure were detected on imaging studies. All patients were hospitalized until day three to five post-trauma, during which GCS and vital data were recorded, including follow-up CT brain scans for detection of early complications.

Patients were then discharged or transferred to other specialized departments for further management when required. All patients were discharged on broad-spectrum oral antibiotics for a further week, then followed up for any appearance of new neurological deficit or delayed complications. GOS was used to assess the functional outcome in our patients (9). Follow-up visits were scheduled at one week, then one, two to three, six and twelve months, according to our departmental protocol, during which CT scans of the brain and/or fundus examination were conducted, depending on the complaint of the patient.

The mean length of hospital stay was $5.1 \pm 2.2$ days and the follow-up duration was $6.8 \pm 2.7$ months. In our cohort, the minimum follow-up for CDFs over venous sinus was $8.3 \pm 1.6$ months. Apio et al. reported that patients with contaminated compound depressed skull fractures treated surgically have to be monitored with repeated CT scans a few times over the next two to three months to search for delayed abscess formation (1). Fred et al. recommended follow-up by repeated CT scans for at least a year for any signs of brain abscess formation (8). Follow-up is also needed to look for the complications associated with skull fractures, for example, seizures, and infections (1).

Thirty-two (94.12\%) patients had a moderate to good outcome using GOS ( $\mathrm{n}=28,82.35 \%)$ with good recovery and four $(11.76 \%)$ with mild disability-grade 4 weakness. Only two patients had severe disability. The pre-treatment motor power for these patients was grade 3 . All the patients were discharged with a GCS of 15 , being fully conscious. There were no cases of infection on follow-up and no cases of mortality.

\section{CONCLUSION}

The majority of simple fractures, and a portion of compound depressed skull fractures, can be managed safely without major surgical intervention. Conservation should be favored when the sinus is patent, and dura intact; bone displacement is insignificant in neurologically-intact patients with an apparently clean wound. Otherwise surgery should be considered, in which case the risk of venous sinus bleeding should be weighed against the benefits of surgery in reducing sepsis from contamination, mass effect, and improving cosmetic appearance. We also recommend considering serial fundus examinations and cerebral venogram as part of the initial trauma work-up and follow-up visits for those patients that are to be managed non-surgically or being susceptible to delayed increased intracranial pressure.

\section{REFERENCES}

1. Antunes ACM, Franciscatto AC, Modkovski R, Torres de Avila T: Depressed skull fracture. In: Kalangu KKN, Kato Y, Dechambenoit G (eds). Essential Practice of Neurosurgery, $1^{\text {st }}$ ed. Nagoya: Access Publishing Co., Ltd, 2009:720-721

2. Braakman R: Depressed skull fracture: Data, treatment, and follow-up in 225 consecutive cases. J Neurol Neurosurg Psychiatry 35(3):395-402, 1972

3. Donovan DJ: Simple depressed skull fracture causing sagittal sinus stenosis and increased intracranial pressure: Case report and review of the literature. Surg Neurol 63(4):380-383, 2005

4. du Plessis JJ: Depressed skull fracture involving the superior sagittal sinus as a cause of persistent raised intracranial pressure: A case report. J Trauma 34(2):290-292, 1993

5. Esene IN, Ngu J, Elzoghby M, El husseiny H, Sikod AM, Deshambnoit G, Solaroglu I, Kotb A: Case series and descriptive cohort studies in neurosurgery: The confusion and solution. Childs Nerv Syst 30(8):1321-1332, 2014

6. Forbes JA, Reig AS, Tomycz LD, Tulipan N: Intracranial hypertension caused by a depressed skull fracture resulting in superior sagittal sinus thrombosis in a pediatric patient: Treatment with ventriculoperitoneal shunt insertion. J Neurosurg Pediatr 6(1):23-28, 2010 
7. Fuentes S, Metellus P, Levrier O, Adetchessi T, Dufour $\mathrm{H}$, Grisoli F: Depressed skull fracture overlying the superior sagittal sinus causing benign intracranial hypertension. Description of two cases and review of the literature. $\mathrm{Br} \mathrm{J}$ Neurosurg 19(5):438-442, 2005

8. Geisler FH, Manson PN: Traumatic skull and facial fractures. In: Rengachary SS, Ellenbogen RG (eds). Wilkins Principles of Neurosurgery. $2^{\text {nd }}$ ed. Elsevier Limited, 2005: 333

9. Jennett $\mathrm{B}$, Bond $\mathrm{M}$ : Assessment of outcome after severe brain damage. Lancet 1(7905):480-484, 1975

10. LeFeuvre D, Taylor A, Peter JC: Compound depressed skull fractures involving a venous sinus. Surg Neurol 62(2):121-125, 2004

11. Mathew JE, Sharma A: Bizarre depressed skull fracture by a tile fragment in a young child, causing superior sagittal sinus injury. Surg Neurol Int 1:52, 2010

12. Miller JD, Jennett WB: Complications of depressed skull fracture. Lancet 2(7576):991-995, 1968

13. Nakagawa $A$, Karibe $H$, Onuma $T$, Hirano $T$, Kameyama $M$, Ishii K: Hemorrhagic infarction complicated by obliteration of the superior sagittal sinus by depressed skull fracture after a hammer injury: A case report. No Shinkei Geka 39(3):287-292, 2011

14. Ozer FD, Yurt A, Sucu HK, Tektas S: Depressed fractures over cranial venous sinus. J Emerg Med 29(2):137-139, 2005
15. Rivkin MA, Saraiya PV, Woodrow SI: Sinovenous thrombosis associated with skull fracture in the setting of blunt head trauma. Acta Neurochir (Wien ) 156(5):999-1007, 2014

16. Taghyan M, Moussa A, Nouby R: Compound depressed skull fractures overlying dural venous sinuses. Pan Arab Jornal of Neurosurgery 12(2):51-55, 2008

17. Tanaka H, Tanaka H, Kobata H: Superior sagittal sinus occlusion caused by a compound depressed skull fracture: A case treated by emergency surgery. No Shinkei Geka 32(7):753-758, 2004

18. van den Brink WA, Pieterman H, Avezaat CJ: Sagittal sinus occlusion, caused by an overlying depressed cranial fracture, presenting with late signs and symptoms of intracranial hypertension: Case report. Neurosurgery 38(5):1044-1046, 1996

19. Yadav YR, Parihar V, Sinha M, Jain N: Simple depressed skull fracture causing posterior third superior sagittal sinus occlusion and elevated intracranial pressure. Neurol India 57(6):830-831, 2009

20. Yokota H, Eguchi T, Nobayashi M, Nishioka T, Nishimura $F$, Nikaido Y: Persistent intracranial hypertension caused by superior sagittal sinus stenosis following depressed skull fracture. Case report and review of the literature. J Neurosurg 104(5):849-852, 2006

21. Zacko JC, Harris L, Bullock RM: Surgical management of traumatic brain injury. In: Bullock MR, Hovda DA (eds). Youmans Neurological Surgery. $6^{\text {th }}$ ed. 2014: 3516-3517 